\title{
Histomorphometrical and Histochemical Studies on Infundibulum of Punjab White Quails
}

\author{
S.V. Sukhadeve ${ }^{1}$, Neelam Bansal ${ }^{2 *}$ and Devendra Pathak $^{2}$ \\ ${ }^{1} G$ H Raisoni University, Chhindwara (MP), India \\ ${ }^{2}$ Department of Veterinary Anatomy, Guru Angad Dev Veterinary and Animal \\ Sciences University, Ludhiana, Punjab 141004, India \\ *Corresponding author
}

\section{Keywords \\ Histology, histochemistry, Micrometry, infundibulum, Punjab White Quails \\ Article Info \\ Accepted: \\ 10 February 2019 \\ Available Online: \\ 10 March 2019}

\section{A B S T R A C T}

The present work was conducted on oviduct of 42 Punjab white quails from 8 weeks to 32 weeks of age to study histological, micrometrical and histochemical details on the cranial and caudal parts of infundibulum. The samples were collected from cranial and caudal parts of infundibulum, processed for paraffin sectioning and were stained with various stains to observe detailed histoachitecture of infundibulum at various age groups. The results revealed that there was numerous of mucosal folds in the cranial part of infundibulum which decreased in the caudal part of infundibulum. The lining epithelium of infundibulum was simple columnar ciliated with ciliated and non-ciliated cells. The proprial glands were mainly present in the caudal part of infundibulum. The amount of fibrous components was less in the infundibulum. The micrometrical studies showed that the length and number of mucosal folds was maximum in the cranial part of infundibulum which decreased in the caudal part. Histochemical observations depicted moderate PAS, bromphenol blue and Sudan Black B reaction was seen in the epithelium whereas moderate to strong PAS/AB activity was observed in infundibular glands and lamina epithelial is in caudal part. The later may be due to the secretory activity in the epithelium and glands. The present study concludes that the histomorphometrical and histochemical data on the infundibulum of Punjab white quails can be correlated with the reproductive status at different age groups.

\section{Introduction}

The avian oviduct is divided into the five segments i.e. infundibulum, magnum, isthmus, uterus/shell gland and vagina. The developing egg remained for $9 \mathrm{~h}$ in the proximal part (infundibulum, magnum or isthmus) and for $39 \mathrm{~h}$ in the distal part of the oviduct (uterus) during the egg laying cycle (Sharaf et al., 2012). Infundibulum plays an important role in capturing out from the body of birds and weights of infundibulum and transferring of ovum and formation of chalaza (Patki et al., 2009). The cranial part of infundibular mucosa is made up of longitudinal folds lined by ciliated epithelium and had no glands, whereas 
the caudal part contained glands which partially mix up with groups glands of magnum (Khokhlov 2008). The literature is available on the histomorphochemical studies have been conducted on the infundibulum of Pati and Chara-Chemballi ducks (Deka et al., 2014), Kuttanad duck (Patki et al., 2009), hen (Khokhlov 2008), ostrich (Sharaf et al., 2012), but few reports are available on the infundibulum of Punjab white quail (Bansal et al., 2010). So, the present study will provide the scientific information on normal histoachitectureand its correlation with any abnormality occurring in the infundibulum of Punjab white quail at different age groups.

\section{Materials and Methods}

The tissue samples were collected from cranial and caudal parts of infundibulum from 42 Punjab white quails of different age groups available at poultry farm, GADVASU, Ludhiana. Based on the age, the birds were divided into seven groups (six in each) as 8 weeks (Group I), 12 weeks (Group II), 16 weeks (Group III), 20 weeks (Group IV), 24 weeks (Group V), 28 weeks (Group VI) and 32 weeks (Group VII). The cranial and caudal parts of infundibulum were collected in NBF by abdominal laprotomy and processed as per routine acetone benzene schedule (Luna 1968). The paraffin sections of 5-6 $\mu \mathrm{m}$ were obtained on glass slides with the help of rotary microtome and were stained with haematoxylin and eosin for general morphology, Masson's Trichrome for collagen fibres, Gridley's for reticular fibres, Verhoeff's for elastic fibres and Holmes's for neuronal elements. For histochemical studies, Periodic acid Schiff and alcian blue at $\mathrm{pH} 2.5$ was performed for demonstration of neutral and acid mucopolysaccharides, and bromphenol blue for basic proteins (Chayen et al., 1969). Fresh tissue samples were subjected to cryostat sectioning at $10 \mu \mathrm{m}$ thickness and incubated to demonstrate the sudanophilic lipids (Pearse 1972). Micrometrical parameters were recorded on Hematoxylin and eosin stained sections by means of standard method of micrometry using Nikon 80 i camera mounted microscope with the help of image $\mathrm{J}$ software. For histochemical studies, the sections

\section{Results and Discussion}

The histological observations showed that infundibulum was made up of four layers viz tunica mucosa, propria submucosa, tunica muscularis and tunica serosa as described by the Banks (1993) in fowl. The cranial and caudal parts of the infundibulum showed following observations.

\section{Tunica Mucosa}

\section{Cranial part}

The mucosa was highly folded (finger like) and branched in cranial part than caudal parts in PWQ. In cranial part, these folds were made up of primary and secondary with branching at the 8 weeks of age, which were larger in size and showed anastomoses at 12 weeks of age (Fig. 1). From 16 weeks of age onwards, there was formation of primary, secondary and tertiary folds which were large finger like and branched. There was less anastomosis in the mucosal folds with increasing age of both the birds at 28 weeks and 32 weeks (Fig. 2). The length of mucosal folds at 8 weeks, 12 weeks, 16 weeks, 20 weeks, 24 weeks, 28 weeks and 32 weeks was measured to be $352.23 \pm$ $9.23 \mu \mathrm{m}, \quad 537.87 \pm 14.65 \mu \mathrm{m}, \quad 558.93 \pm$ $18.42 \mu \mathrm{m}, \quad 672.76 \pm 15.78 \mu \mathrm{m}, 783.64 \pm$ $19.57 \mu \mathrm{m}, 828.84 \pm 13.92 \mu \mathrm{m}$ and $889.28 \pm$ $16.5 \mu \mathrm{m}$, respectively (Table 1). From the present data, it may be concluded that the length of mucosal folds increased with age. Similar findings on the height of mucosal folds were reported in Japanese quail by Mahmud (2014), however, Bansal et al., 
(2010) reported more height of mucosal folds in Punjab white quail. But it was noticed that the height of mucosal folds in Punjab white quail in present investigation was same as observed in Aseel and RIR birds by Lata (2007).

The lining epithelium of infundibulum varied from low columnar to tall columnar ciliated type with more ciliated cells than the secretory cells in cranial part of infundibulum. At the 8 week of age, lamina epithelialis was simple columnar type with oval to rounded nuclei located at the base and at apex in ciliated and non ciliated cells, respectively. The lining epithelium was tall columnar with more ciliated cells at 12 weeks of age and was pseudostratified columnar type at 28 and 32 weeks (Fig. 3). Anastomosis was more prominent at 16 weeks of age in the primary, secondary and tertiary folds and it may form star shaped structure in the lumen at 20 weeks of age. The height of epithelium and cilia were more upto 20 weeks of age in both the birds. There was slight reduce in content of epithelium at 28 weeks and 32 weeks of age. This may indicate the regression process of oviduct at this stage. The epithelial height was less at the grooves in between the mucosal folds as seen at 16 weeks to 32 weeks of age. The height of epithelium was found to be $25.54 \pm 2.04 \mu \mathrm{m}, 27.72 \pm 1.98 \mu \mathrm{m}, 29.97 \pm$ $3.55 \mu \mathrm{m}, 32.18 \pm 7.05 \mu \mathrm{m}, 34.22 \pm 6.28 \mu \mathrm{m}$, $35.83 \pm 4.95 \mu \mathrm{m}$ and $36.34 \pm 2.87 \mu \mathrm{m}$ at 8 weeks, 12 weeks, 16 weeks, 20 weeks, 24 weeks, 28 weeks and 32 weeks, respectively. The height increased from 8 weeks to 24 weeks of age which slightly decreased after 28 weeks of age. Similar height of epithelium in cranial part of infundibulum was observed in Japanese quail by Mahmud (2014) and in Aseel and RIR birds by Lata (2007).

\section{Caudal part}

In caudal part of infundibulum showed the formation of primary folds with shallow invaginations at 8 weeks of age (Fig. 4). The secondary folds may also have observed at the 12 weeks of age and primary folds became larger with small leaf like folds. At 20 weeks of age, in between primary and secondary folds small tertiary folds also had seen. There was reducing in number and size of mucosal folds at the 32 weeks of age. Narrow angular grooves were observed in basal part of mucosal part of caudal part of infundibulum from 8 week of age. The lamina epithelialis was simple columnar type containing more nonciliated cells than ciliated one. The number of non ciliated cells was more and their nuclei were oval to round in shape and situated at the base of the cell. It was also noticed that the lining epithelium was lightly stained as compared to the other components which may be due to presence of more secretory cells in this region (Figs 5 and 6). Berg et al., (2001) also observed that the staining of nonciliated cell was light as compared to ciliated ones in Japanese quail. The results also showed that the number of secretory cells reduced with age of the birds indicating regression process in oviductal mucosa as observed by Mahmud (2014) in Japanese quail

\section{Propria submucosa}

Propria submucosa was made up of fibroblasts, connective tissue, blood vessels, nerves and lymphatics at different stages of development. The collagen fibres were prominent in the propria submucosa and lamina propria of infundibulum along with the reticular and elastic fibres (Fig. 7). The amount of collagen fibres was less in propria submucosa at 8 weeks of age which increased at 32 weeks of age. These fibrous components predominantly coursed circularly in propria submucosa of both of the birds form 20 weeks age onwards. In present study, the nerve fibres could not demonstrated at 8 week of age but very less fine nerve fibres were noticed at 16 weeks onwards in the propria submucosa and serosa layers. The collagen fibres were less in 
number from 8 weeks to 12 weeks of age while reticular, elastic and neuronal fibres were few which increased from the 16 weeks onwards, the collagen and reticular were abundant, whereas elastic and neuronal fibres were less. The propria submucosa of infundibulum contained simple tubular glands reported at 8 weeks of age onwards, which became very prominent at 12 and 16 weeks of age. These glands were lined by cuboidal to low columnar cells which were located in the vicinity at secondary folds. The number and amount of glands were more in the ageing birds. These glands were compactly arranged up to 24 weeks of age (Fig. 5) and were loosely arranged at 28 weeks and 32 weeks of age (Fig. 6). At 32 weeks of age, in between these glands, there were darkly stained tubular glands lined by cuboidal epithelium and had wider lumen, which were morphologically similar to the sperm host glands (Fig. 6).

All the three types of fibres were noticed in propria submucosa and lamina propria layers; among them, collagen fibres were highest in number (Fig. 8), while reticular, elastic and neuronal fibres were few. Collagen fibres were present in the propria submucosa and extending in the core of mucosal folds in both birds from the 8 weeks to 16 weeks of age which increased from the 20 weeks onwards. The elastic fibres were very prominent in the blood vessels of propria submucosa and in between the two layers of tunica muscularis as seen at 12 weeks of age to 32 weeks of age. The amount of neuronal element was seen at propria submucosa and tunica serosa layer at different age group, which increased from 8 weeks to 16 weeks of age.

\section{Tunica Muscularis}

Tunica muscularis was very thin and less developed upto 12 weeks of age which was found to be well developed at 16 weeks of age onwards. This layer was made up of inner circular and outer longitudinal layers from 16 weeks onwards. These layers were separated by stratum vasculare. The smooth muscle bundles of tunica muscularis were scattered and loosely arranged in the cranial part upto 20 week of age, but it was well organized afterwards at 28 weeks and 32 weeks of age (Fig. 2).

The thickness of tunica muscularis was measured at 8 weeks, 12 weeks, 16 weeks, 20 weeks, 24 weeks, 28 weeks and 32 weeks as $13.48 \pm 3.29 \mu \mathrm{m}, 15.76 \pm 6.18 \mu \mathrm{m}, 17.62 \pm$ $7.09 \mu \mathrm{m}, 20.72 \pm 5.37 \mu \mathrm{m}, 21.28 \pm 4.17 \mu \mathrm{m}$, $22.36 \pm 8.13 \mu \mathrm{m}$ and $23.45 \pm 9.34 \mu \mathrm{m}$, respectively. Similar findings were observed by Bansal et al., (2010) in Punjab white quail and Mahmud (2014) in Japanese quail. This layer was well developed in caudal part of infundibulum in all age group studied and was made up of inner circular and outer longitudinal layer which were well demonstrated at 8 weeks of age. Myentric plexus was also observed in between these layers.

\section{Tunica Serosa}

Tunica serosa was also differentiated from 8 weeks age onwards and was consisted of loose connective tissue which was lined by mesothelium (Figs. 1 and 2). There was no evident change in the cellular and fibrous components of this layer with age except that it became thicker in the ageing birds.

The thickness of tunica serosa was measured at 8 weeks, 12 weeks, 16 weeks, 20 weeks, 24 weeks, 28 weeks and 32 weeks as $3.12 \pm 0.8$ $\mu \mathrm{m}, 3.36 \pm 0.12 \mu \mathrm{m}, 3.68 \pm 0.6 \mu \mathrm{m}, 4.18 \pm 0.3$ $\mu \mathrm{m}, 4.87 \pm 0.56 \mu \mathrm{m}, 5.16 \pm 0.21 \mu \mathrm{m}, 5.68 \pm$ $0.5 \mu \mathrm{m}$, respectively. The thickness of serosa was increased from 8 weeks to 32 weeks age.

The histological observations on the cranial part of infundibulum coroborates well with the 
findings of Khokhlov (2008) in hens, Kanchana (2010) in Kadaknath fowl, Garg (2006) in guinea fowl, Lata (2007) in Aseel and RIR birds, Bansal et al., (2010) in Punjab white quail, Mahmud (2014) in Japanese quail, Deka et al., 2014 in Pati and CharaChemballi ducks.

The present histological study in caudal part of infundibulum was closely related to the observations of Lata (2007) in Aseel and RIR birds, Mohammadpour and Keshtmandi (2008) in turkey and pigeon, Ozen et al., (2009) in Pekin duck, Bansal et al., (2010) in Punjab white quail, Mihirish and Nasif (2013) in turkey, Deka et al., (2014) in Pati and Chara-Chemballi ducks, Muhmud(2014) in Japnese quail and Essam et al., (2016) in duck.

\section{Histochemical Observations}

The histochemical findings on the cranial and caudal parts of infundibulum have been summarized in Table 2.

\section{Mucopolysaccharides}

A mild to moderate $\mathrm{PAS}-\mathrm{AB}$ reaction was seen in the lamina epithelialis of infundibulum from 8 weeks of age onwards. The reaction was more in the supranuclear part than the infranuclear part of the epithelial cells and cilia (Fig. 9). The secretory blebs also showed moderate PAS reaction, whereas basement membrane showed weak activity. The reaction was prominent in secretory cells than the ciliated cells in caudal part of infundibulum (Fig. 11).

Table.1 Micrometrical observations on different layers of infundibulum in Punjab white quail (Mean \pm SE $\mu \mathrm{m})$

\begin{tabular}{|l|l|l|l|l|}
\hline Age & $\begin{array}{l}\text { Length of } \\
\text { mucosal folds }\end{array}$ & $\begin{array}{l}\text { Height of } \\
\text { epithelium }\end{array}$ & $\begin{array}{l}\text { Thickness of } \\
\text { Tunica Muscularis }\end{array}$ & $\begin{array}{l}\text { Thickness of } \\
\text { Tunica Serosa }\end{array}$ \\
\hline 8 week & $352.23 \pm 9.23$ & $25.54 \pm 2.04$ & $13.48 \pm 3.29$ & $3.12 \pm 0.8$ \\
\hline 12 week & $537.87 \pm 14.65$ & $27.72 \pm 1.98$ & $15.76 \pm 6.18$ & $3.36 \pm 0.12$ \\
\hline 16 week & $558.93 \pm 18.42$ & $29.97 \pm 3.55$ & $17.62 \pm 7.09$ & $3.68 \pm 0.6$ \\
\hline 20 week & $672.76 \pm 15.78$ & $32.18 \pm 7.05$ & $20.72 \pm 5.37$ & $4.18 \pm 0.3$ \\
\hline 24 week & $783.64 \pm 19.57$ & $34.22 \pm 6.28$ & $21.28 \pm 4.17$ & $4.87 \pm 0.56$ \\
\hline 28 week & $828.84 \pm 13.92$ & $35.83 \pm 4.95$ & $22.36 \pm 8.13$ & $5.16 \pm 0.21$ \\
\hline 32 week & $889.28 \pm 16.57$ & $36.34 \pm 2.87$ & $23.45 \pm 9.34$ & $5.68 \pm 0.5$ \\
\hline
\end{tabular}

Table.2 Histochemical observations on different layers of infundibulum in Punjab white quail

\begin{tabular}{|c|c|c|c|c|}
\hline \multirow{2}{*}{$\begin{array}{l}\text { Histochemical } \\
\text { moieties }\end{array}$} & \multicolumn{4}{|c|}{ Tunics of oviduct } \\
\cline { 2 - 5 } & $\begin{array}{c}\text { Lamina } \\
\text { epithelialis }\end{array}$ & $\begin{array}{c}\text { Propria } \\
\text { submucosa }\end{array}$ & $\begin{array}{c}\text { Tunica } \\
\text { muscularis }\end{array}$ & Tunica serosa \\
\hline Neutral Mucopolysaccharides & $++/+++$ & ++ & ++ & $+/++$ \\
\hline Acidic Mucopolysaccharides & $++/+++$ & $++/+++$ & $+/++$ & $+/++$ \\
\hline Basic proteins & $+/++$ & $++/+++$ & $+/++$ & $+/++$ \\
\hline Sudanophilic lipids & $++/+++$ & $+/++$ & $0 /+$ & $0 /+$ \\
\hline
\end{tabular}


Fig.1 Paraffin section of cranial part of infundibulum of PWQ at 12 weeks of age showing highly folded mucosa (TM), propria submucosa (PS), tunica muscularis (TMM) and tunica serosa (TS). Haematoxylin and eosin stain X 100

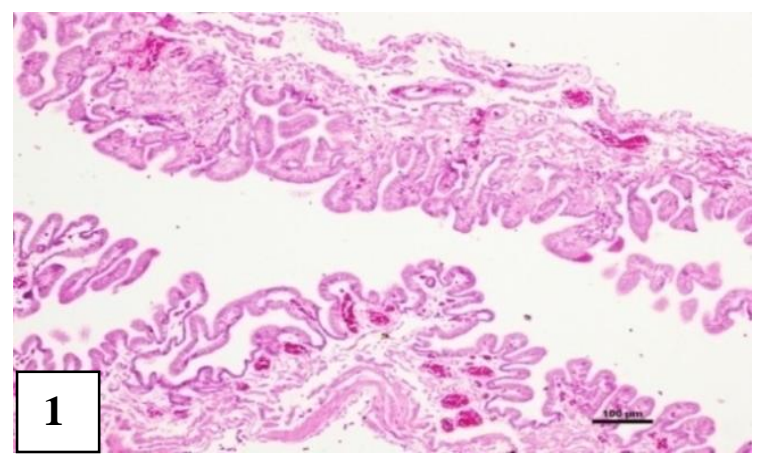

Fig.3 Higher magnification of Fig. 2 showing pseudostratified columnar epithelium (Ep) and propria submucosa (PS). Haematoxylin and eosin stain X 400

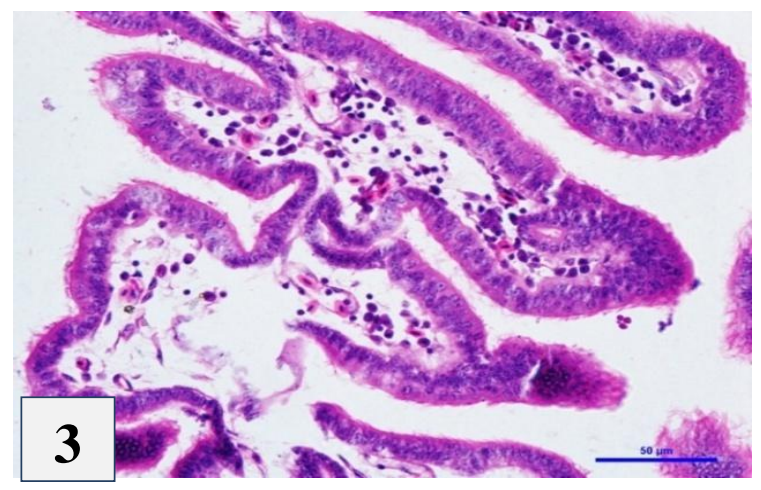

Fig.5 Paraffin section of caudal part of infundibulum of PWQ at 24 weeks of age showing lamina epithelialis (LE) and mucosal glands (MG). Haematoxylin and eosin stain X 400

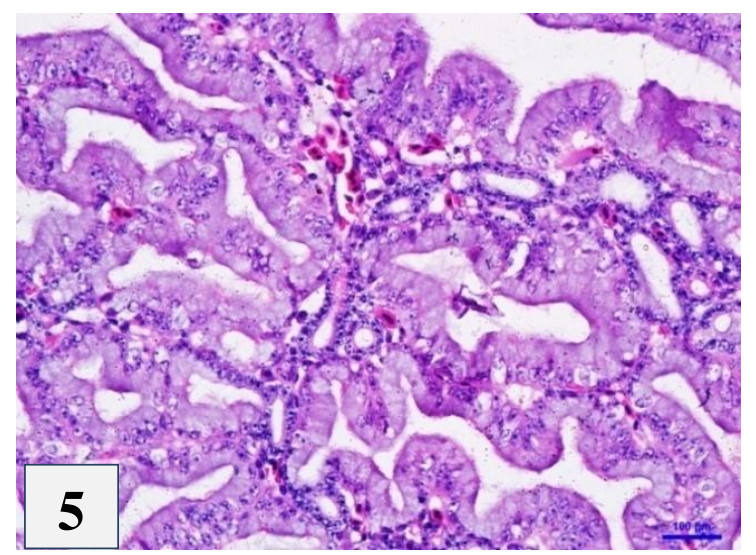

Fig.2 Paraffin section of cranial part of infundibulum of PWQ at 32 weeks of age showing highly folded mucosa (TM), propria submucosa (PS), tunica muscularis (TMM) and tunica serosa (TS). Haematoxylin and eosin stain X 100

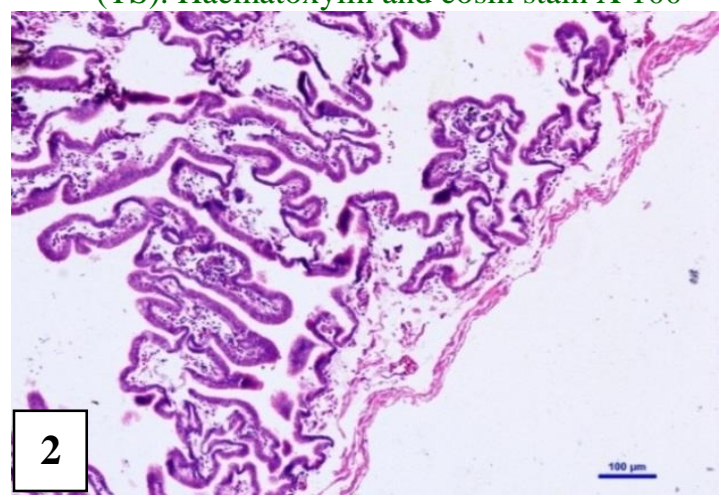

Fig.4 Paraffin section of caudal part of infundibulum of PWQ at 8 weeks of age showing lamina epithelialis (LE), propria submucosa (PS) and mucosal glands (MG). Haematoxylin and eosin stain X 400

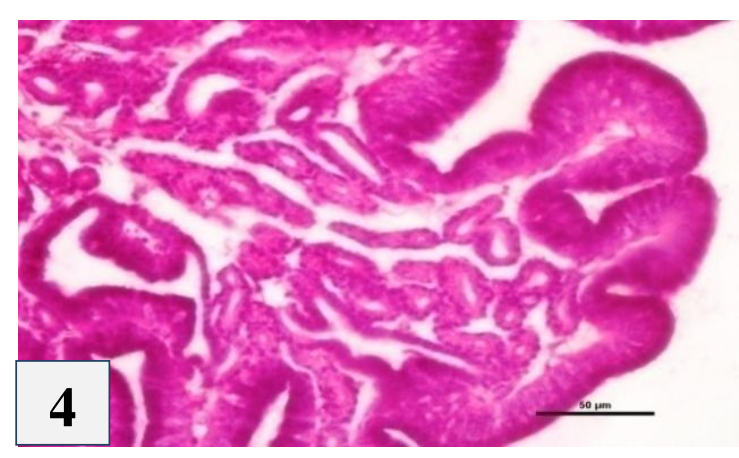

Fig.6 Paraffin section of caudal part of infundibulum of PWQ at 32 weeks of age showing lamina epithelialis (LE), mucosal glands (MG) and proprial glands (PG). Haematoxylin and eosin stain X 400

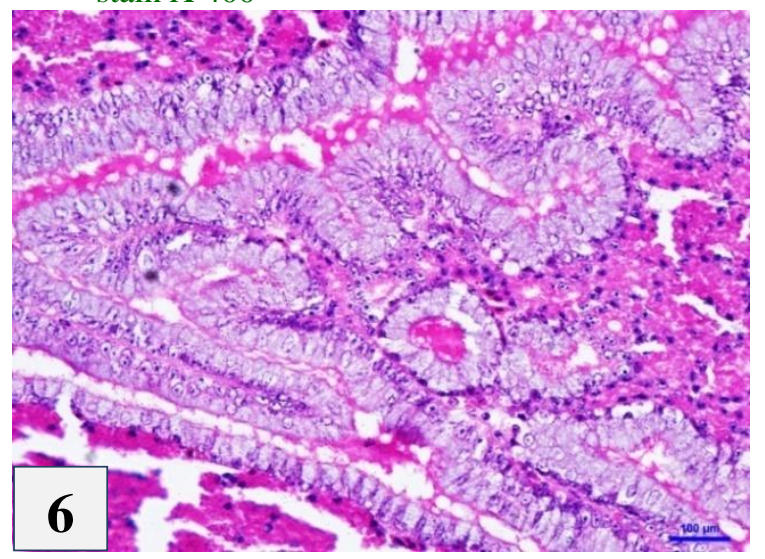


Fig.7 Paraffin section of cranial part of infundibulum of PWQ at 8 weeks of age showing elastic fibres in blood vessels. Verhoeff's stain X 400

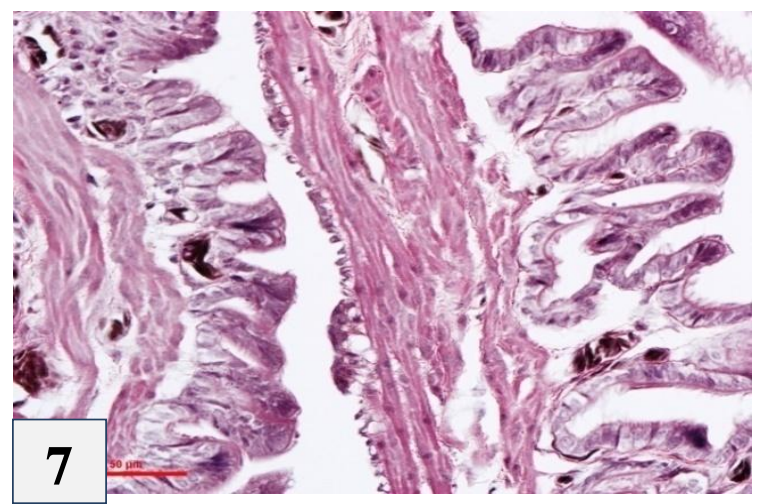

Fig.9 Paraffin section of cranial part of infundibulum of PWQ at 12 weeks of age showing moderate to strong $\mathrm{PAS} / \mathrm{AB}$ reaction in tunica mucosa $(\mathrm{TM})$ and propria

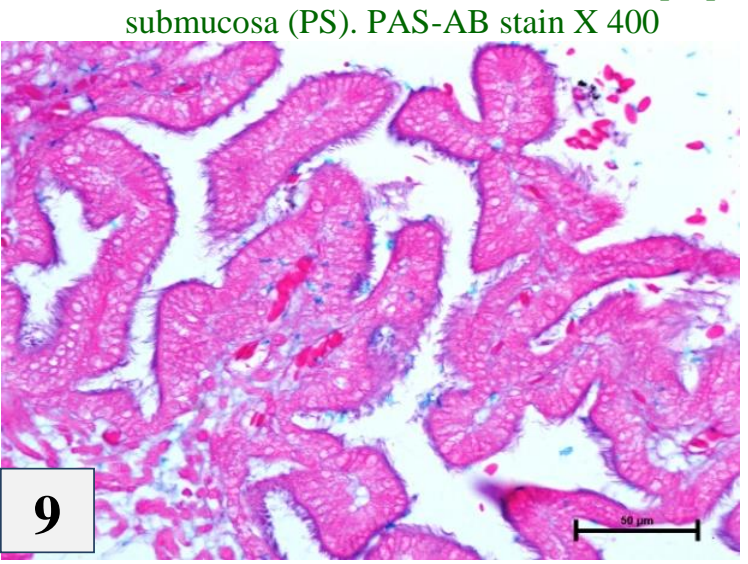

Fig.11 Paraffin section of caudal part of infundibulum of PWQ at 20 weeks of age showing strong PAS and weak to moderate $A B$ reaction in lamina epithelialis

(LE) and moderate to strong PAS-AB reaction in mucosal glands (MG). PAS-AB stain X 400

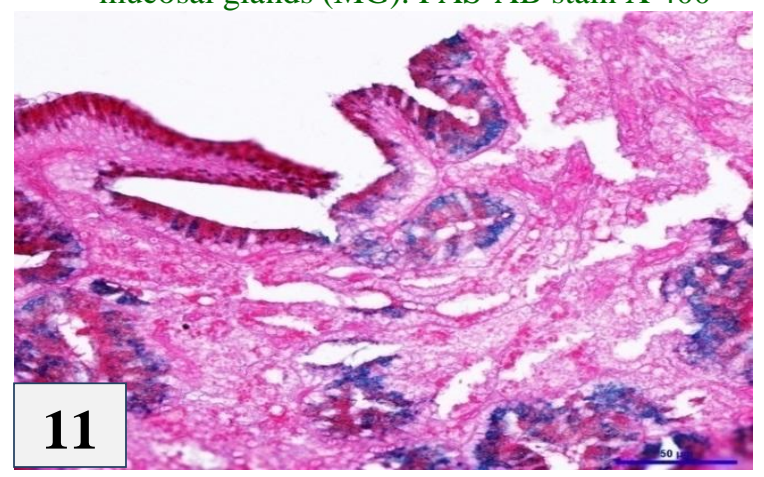

Fig.8 Paraffin section of caudal part of infundibulum of PWQ at 12 weeks of age showing collagen fibres in propria submucosa. Masson's trichrome stain X 400

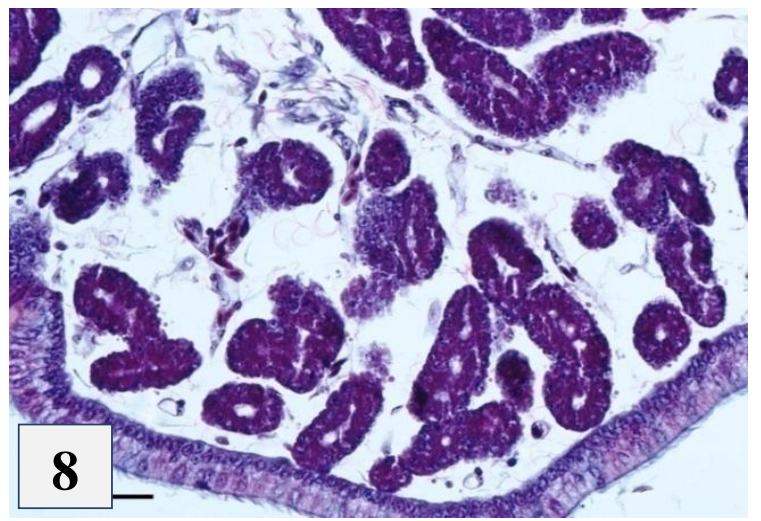

Fig.10 Paraffin section of cranial part of infundibulum of PWQ at 12 weeks of age showing moderate to strong $\mathrm{PAS} / \mathrm{AB}$ reaction in tunica mucosa (TM) and propria submucosa (PS), weak to moderate in tunica muscularis (TMM) and tunica serosa (TS). PAS-AB stain X 400

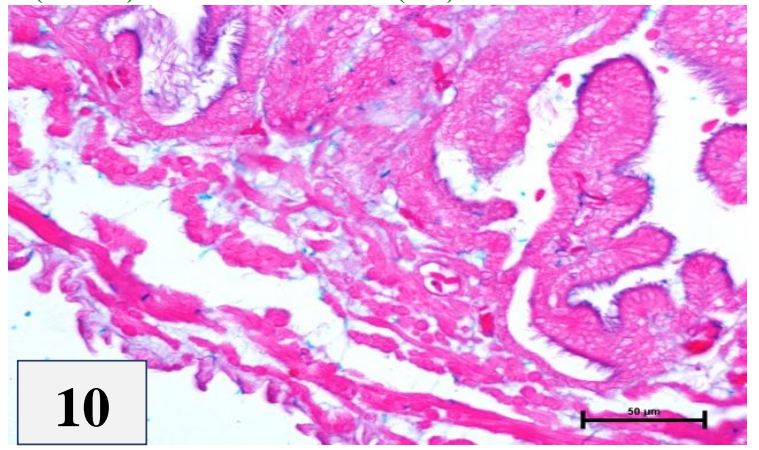

Fig.12 Paraffin section of cranial part of infundibulum of PWQ at 12 weeks of age showing moderate bromphenol blue reaction in lamina epithelialis (LE) and moderate to strong in cilia. Bromphenol blue stain $\mathrm{X} 400$

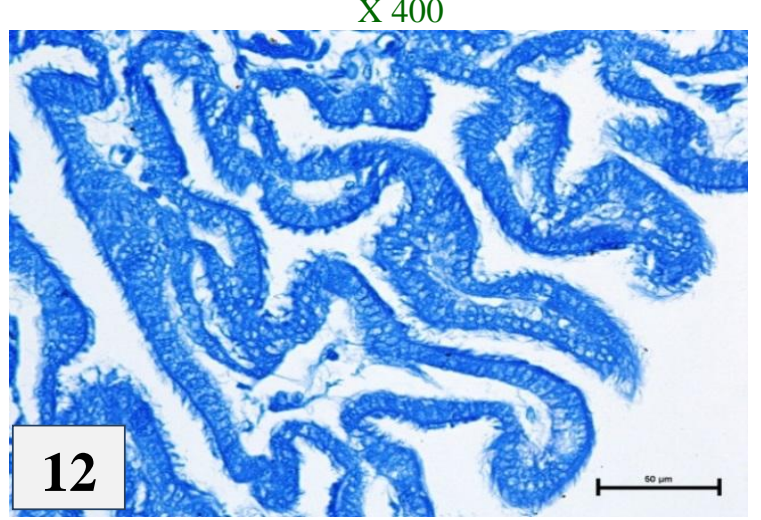


Fig.13 Paraffin section of cranial part of infundibulum of PWQ at 20 weeks of age showing moderate bromphenol blue reaction in tunica muscularis (TMM) and moderate to strong in blood vessels. Bromphenol

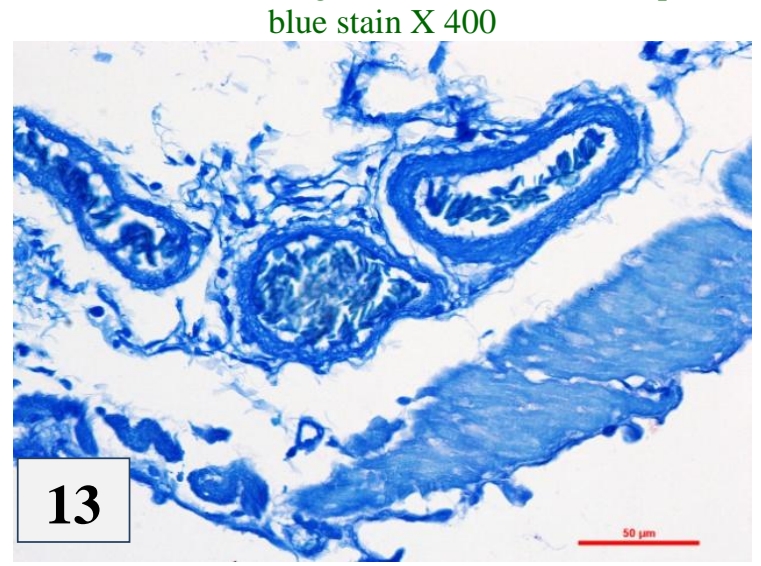

Fig.15 Cryostat section of cranial part of infundibulum of PWQ at 20 weeks of age showing moderate to strong reaction of sudanophilic lipids in tunica mucosa (TM) and negligible to weak in propria submucosa (PS), tunica muscularis (TMM) and tunica serosa (TS). Sudan Black B stain X 100

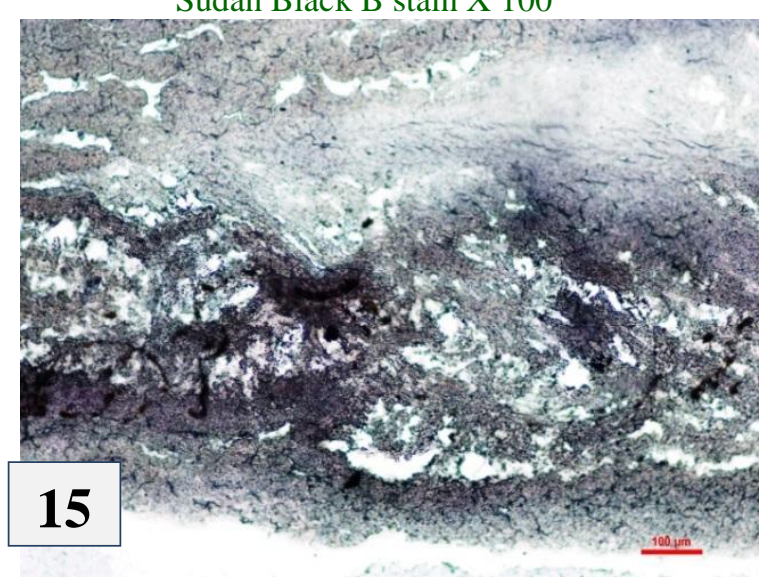

The cranial part of infundibulum showed moderate $\mathrm{PAS}$ reaction and weak $\mathrm{AB}$ reaction in the ciliated cells, whereas reverse activity in the caudal part of infundibulum. Similar observations in emu bird by Vijayakumar et al., (2016), by Ozen et al., (2009) in pekin duck, Bansal et al., (2010) in Punjab white quail and RIR and Asseel birds by Lata (2007). The PAS AB activity was moderate to strong also observed in infundibular glands (Fig. 11), however Vijayakumar et al., (2016) could not demonstrate acid
Fig.14 Paraffin section of caudal part of infundibulum of PWQ at 16 weeks of age showing weak bromphenol blue reaction in lamina epithelialis (LE) and moderate to strong in propria submucosa (PS). Bromphenol blue stain X 400

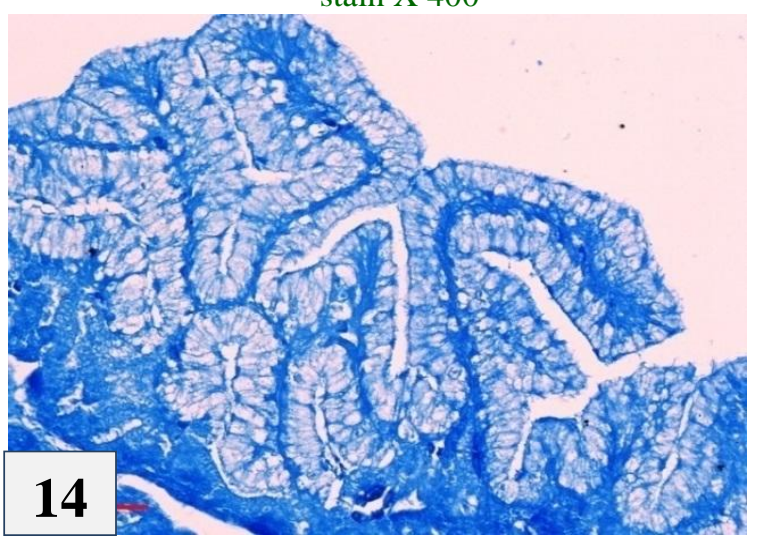

Fig.16 Cryostat section of caudal part of infundibulum of PWQ at 20 weeks of age showing weak to moderate of sudanophilic lipids in different layers and negligible to weak in mucosal glands (MG). Sudan Black B stain $\mathrm{X} 100$

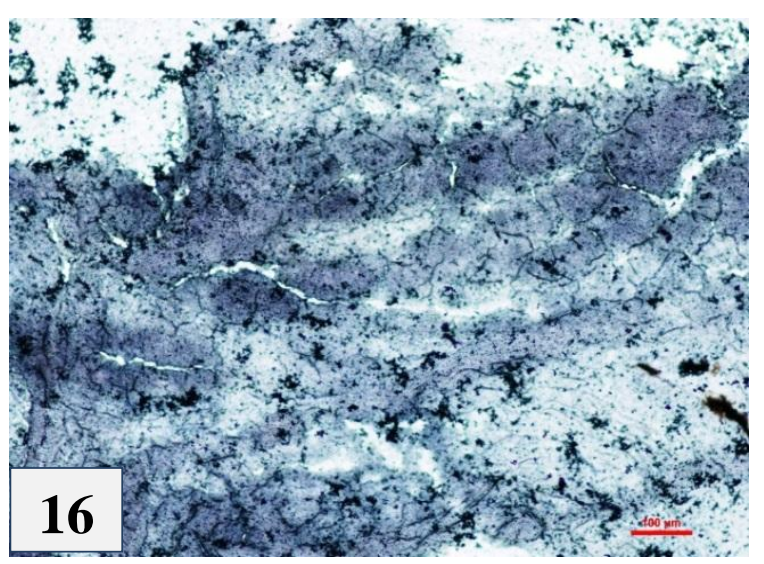

mucopolysacchrides in tubular glands of emu oviduct.

Tunica muscularis and tunica serosa layers of infundibulum showed weak to moderate PAS activity (Fig. 10). The apical portion of the lining epithelium of the infundibular funnel showed strong PAS positive reaction, which agreed with the reports of Saber et al., (2009). In contrary to this Sharaf et al., (2012) reported a negative PAS reaction in the ciliary zone of surface epithelium in ostrich. The 
connective tissue of propria submucosa also showed strong PAS positive reaction, which is identical to the observation made by Sharaf et al., (2012) in ostrich. Strong PAS positive reaction was observed in the supranuclear region of the surface epithelium and the cells lining the glandular tubules in the infundibular tubal part. This feature was agreed completely with the reports in ostrich by Sharaf et al., (2012). However, in our study strong PAS positive reaction was also observed in the supranuclear region of the surface epithelium and the cells lining the glandular tubules in the infundibular funnel. However, most of the cytoplasm of the glandular tubules at the infundibular tubal was found to be exhibited a strong PAS positive reaction by Sharaf et al., (2012) in ostrich. In present study, PAS positive reaction was observed strongly in the luminal borders and the secretions in the lumen of glandular secretary units. However, a negative PAS reaction was reported to be noticed in the luminal border of glandular units in ostrich by Sharaf et al., (2012) in contrary to the present findings.

\section{Basic proteins}

The lamina epithelialis of cranial part of infundibulum showed moderate reaction for bromphenol blue from 12 to 32 week age (Fig. 12). The intensity of localization of protein was more in the cilia of ciliated cells and secretory blebs of non secretory cells. laminapropria, tunica muscularis and tunica serosa layers showed weak to moderate bromphenol blue activity in cranial part, however RBCs in blood vessels showed very strong reaction for basic protein (Fig. 13).

Lamina epithelialis of the caudal part of infundibulum showed weak activity for protein but strong activity in infundibular glands (Fig. 14). Similar findings were observed in the infundibulum of PWQ by
Bansal et al., (2010), in laying and non-laying emu birds by Vijayakumar et al., (2016) and domestic duck by Rao (1994). The presence of proteins in the epithelial part of cranial part and proprial glands of caudal part may be due to active mode in transportation of sugar and amino acid (Nelson and Cox 2005).

\section{Sudanophilic lipids}

Lamina epithelialis of the cranial part of infundibulum showed moderate to strong reaction, propria submucosa, tunicamuscularis had weak to moderate reaction but tunica serosa showed negligible to weak reaction of sudanophilic lipids (Fig. 15). The activity was same in caudal infundibulum, propria submucosa (Fig. 16) whereas it was increased to moderate in proprial glands as observed by Bansal et al., (2010) in Punjab white quail and Vijayakumar et al., (2016) in duck. It was also noticed that the activity was more in the supranuclear region than infranuclear region of lamina propria. Sudanophiliclipids were also located in the secretory blebs and the cilia in the luminal part.

From the present study, it may be concluded that the number of mucosal folds and ciliated cells were more in the cranial part of infundibulum which may help in capturing of ovum as and when released. The tubular glands present the caudal part of infundibulum were well developed at 38 weeks which is the active phase of reproduction in Punjab white quail. The acidic and neutral mucopolysachharides were more in different layers of caudal part due to the more secretory activity of this part.

\section{References}

Banks, W. J. 1993. Applied Veterinary Histology St Louis: Mosby Year Book. London. $3^{\text {rd }}$ Edition. pp: 465.

Bansal, N., Uppal, V., Pathak, D. and Brah, 
G. S. 2010.Histomorphometrical and Histochemical studies on the oviduct of Punjab White quails. Indian Journal of Poultry Science45: 88-92.

Berg, C., Holm, L., Brandt, I. and Brunström, B. 2001. Anatomical and histological changes in the oviducts of Japanese quail, Coturnix japonica, after embryonic exposure to ethynyloestradiol. Reproduction 121: 155-65.

Chayen, J., Bitensky, L., Butcher, R. G. and Poulter L W. 1969. A guide to practical histochemistry. Oliver and Boyd, Edinburgh, England. pp: 83-174.

Deka, A., Baishya, G., Sarma, K.and Bhuyan, M. 2014. Comparative anatomical study on infundibulum of Pati and CharaChembali ducks (Anas platyrhynchos domesticus) during laying periods, Veterinary World7: 271-74.

Essam, M., Gendy, E. L., Asmaa, M. I., Samah, H., El-Bably, Nora, A. S. and Shaimaa, H. H. 2016. Morphological and Histological Studies on the Female Oviduct of Balady Duck (Anas boschas domesticus) International Journal of Advanced Research in Biological Sciences3: 171-80.

Garg, V. K. 2006. Gross morphological, Histological and Ultrastructural studies on oviduct of Kadaknath fowl. Thesis submitted G. B. Pant University of Agriculture and Technology. Pantanagar (Uttaranchal).

Kanchana, R. 2010. Gross Anatomical, Histological and Biometrical studies on Oviduct of Guinea Fowl (Numida meleagris). Thesis submitted G.B.Pant University of Agriculture and technology, Pantanagar (Uttaranchal).

Khokhlov, R. Y. 2008. Morphology of an infundibulum of the oviduct of the sexually mature hens. International Journal of Morphology 26: 883-86.

Lata, K. 2007. Studies on gross histomorphology and Histochemistry of female genitalia of Aseel and Rhode Island Red fowl. M.V.Sc. Thesis, Indira Gandhi Krishi Vishwavidyalaya. Raipur.

Luna, L. G. 1968. Manual of histological staining methods of armed forces Institute of Pathology McGraw Hill Book Company, New York, USA. 3rd Edition pp: 38-196.

Mahmud, M. A. 2014. Anatomy of the oviduct of Japanese quail (Coturnix coturnix japonica) with haematological and biochemical parameters at prelaying, laying and post-laying stages. M.Sc. Thesis, Bangladesh Agricultural University, Mymensingh.

Mirhish, M. S. and Nsaif, H. R. 2013. Histological study of the ovary and infundibulum of Tukey hen (Meleagris gallopavo). Basrah Journal of Veterinary Research 12:11-16.

Mohammadpour, A. A. and Keshtmandi, M. 2008. Histomorphometrical study of infundibulum and magnum in Turkey and Pigeon. World Journal of Zoology3: 47-50.

Nelson, D. and Cox, M. 2005. Lehninger Principles of Biochemistry 4th Edition W. H. Freeman and Company, New York. Pp: 1216

Ozen, A., Ergun, E. and Kurum, A. 2009. Light and electron microscopic studies on the Oviduct epithelium of the Pekin duck (Anas platyrhynchos). Ankara ÜniversitesiVeterinerFakültesiDergisi5 6: 177-81.

Patki, H. S., Lucy, K M, Harshan, K. R. and Chungath, J. J. (2009) Morphological studies on the infundibulum of Kuttanad duck (Anas platyrhynchosdomesticus) during postnatal life. Journal of Veterinary Animal Science. 40: 22-25.

Pearse, A. G. E. 1972. Histochemistry: Theoretical and Applied. Vol.II. Churchill Livingstone, London. $4^{\text {th }}$ 
Edition. pp: 835.

Rao, T. S. C. 1994. Microanatomical studies of male and female reproductive tract of domestic duck (Anas boschusdomesticus). Ph.D. thesis submitted to the Tamil Nadu Agricultural University, Coimbatore, Chennai.

Saber, A. S., Emara, S. A. M. and Abosaeda, O. M. M. 2009. Light, Scanning and transmission electron microscopical study on the oviduct of the ostrich (Struthiocamelus). Journal of
Veterinary Anatomy 2:79-9.

Sharaf, A., Eid, W. and Atta, A. A. 2012.Morphological aspects of the ostrich infundibulum and magnum. Bulgarian Journal of Veterinary Medicine 15: 145-59.

Vijayakumar, K., Paramasivan, S. and Madhu, N. 2016. Microanatomy on oviduct of Laying and Non-Laying Emu Birds. (Dromaius novaehollandiae). International Journal of Agricultural Science and Research 6: 89-96.

\section{How to cite this article:}

Sukhadeve, S.V., Neelam Bansal and Devendra Pathak. 2019. Histomorphometrical and Histochemical Studies on Infundibulum of Punjab White Quails. Int.J.Curr.Microbiol.App.Sci. 8(03): 939-949. doi: https://doi.org/10.20546/ijcmas.2019.803.112 